\title{
A Stage Analysis of the Main Inputs and Outputs of China's Health Reform
}

\author{
Feng Deng ${ }^{1,3}$, Juhong $\mathrm{Lv}^{2}$, Honglin Wang ${ }^{3}$, Jianmin Gao ${ }^{4, *}$ \\ ${ }^{1}$ Health Science Center, Xi'an Jiao Tong University, Xi'an, China \\ ${ }^{2}$ Baoji Central Hospital, Baoji, China \\ ${ }^{3}$ Baoji Center for Disease Control and Prevention, Baoji, China \\ ${ }^{4}$ School of Public Policy and Administration, Xi'an Jiao Tong University, Xi'an, China
}

\section{Email address:}

bjsdf@126.com (Feng Deng), 1jh464@163.com (Juhong Lv), bjcdcmbk@163.com (Honglin Wang), gaojianmin2016@126.com (Jianmin Gao)

\section{To cite this article:}

Feng Deng, Juhong Lv, Honglin Wang, Jianmin Gao. A Stage Analysis of the Main Inputs and Outputs of China's Health Reform. Science Journal of Public Health. Vol. 4, No. 2, 2016, pp. 100-106. doi: 10.11648/j.sjph.20160402.14

\begin{abstract}
This paper analysis the main input and output of China's health reform from 2009 to 2013, the main purpose is find the main problems of China's health reform, and put forward policy recommendations, to provide references for the improvement of China's health reform and other national health reform in the future. The paper uses the method of empirical data analysis, the relevant data from the Chinese government statistics yearbook. Study found, although China's health reform has been implemented for seven years, China's health care model is still the center of disease treatment. Such health care model not only did not effectively reduce the medical burden of residents, but also did not improve the health level of residents. In fact, the health of the Chinese population is declining. Therefore, China should change the center of health care as soon as possible, from disease treatment to disease prevention, in order to improve the input and output performance of health care.
\end{abstract}

Keywords: Healthcare Reform, Input and Output, China

\section{Introduction}

China, the country with the most population in the world, has made remarkable progress in economic and public health over the past 20 years, including prolonged life expectancy by one third, decreased childhood mortality rates by more than half, and increased hospital beds by three times. [1] However, China still faces challenges in many aspects of healthcare system. [2] Therefore, The Chinese government launched a health care reform in 2009, which goaled to establish a basic universal healthcare system to China's more than 1.3 billion citizens, planning to achieve the overall goal to 2020. [3] (1) China's healthcare reform has several achievements at its middle stage in 2013. Over $90 \%$ of residents were covered by basic health insurances across the nationwide. [4] (2) However, the dissatisfaction of patients was high, and the conflicts between patients and doctors or hospitals were kept increased. [5] (3) Furthermore, the prevalence of chronic diseases was rising along with population aging. [6]

The present study was to retrospectively examine the changes of China healthcare system in the distribution of healthcare resources, the contributions of healthcare expenditures among government, residents and other sources, and the prevalence of chronic diseases. We expected to provide evidence of achievement at the mid-term of healthcare reform by comparing the numbers each year, which might give us direction for future.

\section{Data and Methods}

\subsection{Data Source}

The data for present study were collected from the following four public resources: (1) The data of distribution of healthcare professionals were obtained from "the Statistical Bulletin of China's Health Development" issued by National Health and Family Planning Commission every year during 2009-2013; (2) The data of government health expenditure were obtained from Annual National Public Fiscal Expenditure Data released by the Financial Ministry of the People's Republic of China from 2009 to 2013; (3) The data on the prevalence rate of chronic diseases, two-week prevalence 
rate, residents' medical service demand and utilization of health service were obtained from the Fourth and Fifth National Health Care Survey in 2008, and 2013; (4) The data of the total healthcare expenditures, medical expenditures, and out-of-pocket payment were obtained by China statistical yearbook in 2014 .

\subsection{Definitions}

In China, health care human resources include medical and healthcare professionals (physicians, physician assistants, dentists, obstetrics, registered nurses, pharmacists, physiotherapists, optometrists, and others.) and healthcare-associated professionals, who support implementation of health care, include public health administrations, medical educators, medical research scientist, and other supportive staffs who work at hospital.

The health care human resources allocate to hospitals, primary care facilities, and public health institutes (PHIs). Hospitals in China are organized as a 3-tier system as Primary, Secondary or Tertiary institutions, according to hospital's ability to provide medical care, medical education, and conduct medical research. The primary care facilities include township health care clinics at rural districts, community health care clinics and service center at urban areas. PHIs are nonprofit organizations that improve the public's health by fostering innovation, leveraging resources, and building partnerships across sectors, including government agencies, communities, the health care delivery system, media, and academia.

Total health care expenditures included government expenditures, social expenditures, and out-of-pocket payments of the populations. Government expenditures referred to expenditures incurred by the central and local government authorities, including spending on healthcare and population and family planning, subsidy to health insurance, and health administration costs; Social expenditures referred to expenditures incurred by social funds, including spending on social health insurances, private health insurance, and social-medical assistance and donation, and administration cost; Out-of-pocket expenditures for health care that weren't reimbursed by any kinds of insurance scheme, including deductibles, coinsurance, and copayments for covered services plus all costs for services that weren't covered. Out-of-pocket health care expenditures per capita were calculated as the sum of total health care expenditure of the population divided by the number of population. The social health insurance scheme in China health care system included new rural cooperative medical scheme (NCMS), the urban resident basic medical insurance (URBMI), and urban employee basic medical insurance (UEBMI).

\subsection{Indicators}

(1) Two-week prevalence of illness referred to the number of the diagnosed patients among subjects during the two-week survey, divided by the total subjects of survey.

(2) Chronic disease was defined as any non-communicable conditions that typically lasted for a year or more and required ongoing medical attention and/or limited activities of daily living. The prevalence of chronic diseases referred the numbers of patients suffering from chronic conditions within half a year of the survey in the total population of that year.

(3) The annual average number of visiting $=$ the total number of visiting of the year/ the population of the year.

(4) The annual average in-hospital rate $=$ the total number of the discharged from hospital of the year / the total population of the year $\times 100 \%$.

(5) Percentage of out-of-pocket health care expenditures per capita in total health care expenditures = out-of-pocket health care expenditures per capita / (out-of-pocket health care expenditures per capita + Social insurance expenditures (NCMS + URBMI + UEBMI) $\times 100 \%$.

(6) The out-of-pocket health care expenditure per capita as a percentage of average annual household living consumption expenditure per capita was used as a proxy indicator to estimate the financial burden of healthcare placed on population. Annual household living consumption expenditure per capita was defined as total consumption expenditure for daily life including food, clothing, housing, education, health care, transportation etc.

\section{Results}

\subsection{Main Input of China's Health Care Reform from 2009 to 2013}

\subsubsection{The Health Care Human Resources}

In China, above half of professionals allocated in hospitals, and over one third of them allocated in primary care facilities and about $10 \%$ of professionals worked in the public health institutions. Most important, the allocation of professionals had one-direction changes during 2009-2013. As shown in Table 1, about $4 \%$ of medical and healthcare professionals and $3.5 \%$ of healthcare-associated professionals migrated from primary health care facilities to hospitals or the public health institutions. The professionals in public health care institutes have no significant changes. Among them, the healthcare-associated professionals were 1.4 fold of medical and healthcare professionals, and had no significant changes between 2009 and 2013 (1.4 vs. 1.36 fold) as shown in Table 1.

\subsubsection{Healthcare Financial Resources}

From 2009 to 2013, the total healthcare expenditures in China increased about 1.8 fold from 17.5 to 31.7 Trillion RMB, progressively. All sources of expenditures, including government expenditures, social expenditures, and out-of-pocket expenditures of the populations, had significant increases, $1.98,1.85,1.63$ fold, respectively, as shown in Table 2. Moreover, the percentage of government expenditures in total expenditures was increased progressively from 27.5 to $30.1 \%$, but the percentage of out-of-pocket expenditures was decreased progressively from 37.5 to $33.9 \%$, 
while social expenditures has no significant changes, between 34.6 and $36.0 \%$. In 2009 , the percentage of government expenditures was slightly above one quarter of total expenditures.

\subsubsection{Components of China Government Health Care Expenditure}

As shown in Table 3, China government health care expenditure had increased over 2 fold from 399 to 827 billion RMB. Fig. 1 depicted the top 4 categories comprised the majority of the expenditure (about $80-90 \%$ of the total), including Hospitals, Primary Care, Public Health care, Social Basic Medical Insurance. The five years growth trends of these top 4 components of China's government expenditure on health were shown in Fig 1. The same top 4 components as a percentage were shown in Fig 2. Social Basic Medical Insurance had always been the dominant expenses in percentage of government health care expenditure, and had a rapid increase over 2 folds in absolute spending and over half of government health care expenditure in percentage. From 2009-2013, the cost of hospital facilities $(19 \%$ to $14 \%$ of government health care expenditure) had been growing steadily, but had been overtaken in importance by public health care (from $7 \%$ to $15 \%$ of government health care expenditure). The primary care maintained the lowest and relatively constant share of overall cost ( $10 \%$ of government expenditure on health care) from 2009-2013. (Table 3)

\subsection{Main Output of China's Healthcare Reform from 2009 to 2013}

\subsubsection{Two-Week Prevalence and Chronic Disease Prevalence}

The data of population two-week prevalence came from the Chinese Fifth National Health Service Survey, which conducted in 2013. The population of two-week prevalence was $24.1 \%$ in 2013 , which increased $5.2 \%$ compared to that of the fourth survey in 2008. The population of the chronic disease prevalence in age 15 and over in 2013 was $33.1 \%$, which $9 \%$ more than that in 2008. [7]

\subsubsection{Healthcare Service Utilization Rate}

As shown in Table 4, the overall annual patient visiting increased progressively between 2009 and 2013 (54.9 vs. 73.1 billion visitors per year). Adjusted to population, the average annual clinic visiting per person was increased as well, 4.2 visits in 2009 , vs. 5.4 visits in 2013 . The overall number of annual hospital discharged also increased from 133 million in 2009 to 192 million in 2013. The hospital admission rates had significant and progress increases from $9.9 \%$ in 2009 to $14.1 \%$ in 2013 . The total numbers of annual discharged also increased yearly, from 132 million in 2009 to 192 million in 2013, corresponding hospitalization rate from $9.9 \%$ to $14.1 \%$.

\subsubsection{Residents' Medical Burden}

At present, China's medical aid and commercial health insurance spending less. According to data released by the
Ministry of finance of the people's Republic of China and the China Insurance Regulatory Commission, 2013 China Medicaid spending 186.84 billion Yuan RMB, [8] health insurance indemnity and payment 41.113 billion US dollars, [9] and accounted for only when personal cash health expenditures and health care spending sum of $2.9 \%$ (597.97/20 439.54 billion Yuan RMB). As a result, the medical expenses of Chinese residents are mainly borne by the individual and the basic medical insurance. As shown in Table 5, in 2009, China spent 1.8 trillion, or 5.15 percent of its gross domestic product (GDP), on health care. However, it rapidly increased to 3.2 trillion at 2013 , but the percentage in GDP slightly increased to $5.57 \%$. Furthermore, out-of-pocket money from individual as a financial burden increased from 0.7 trillion in 2009 to 1.1 trillion in 2013 . Furthermore, as largest part of healthcare spending pie, its share as a percentage of total spending for healthcare was declining, from $64.9 \%$ in 2009 to $52.5 \%$ in 2013 . It also noted that the major portion of spending in healthcare went toward basic medical insurance, and those funds were rising significantly from 355 billion to 971 billion. Other contributions came from social insurance expenditures (NCMS + URBMI + UEBMI), increased as well, including NCMS from 92 billion to 291 billion, URBMI from 41 billion (since 2011) to 97 billion, and UEBMI 263 billion to 583 billion.

\subsection{Figure}

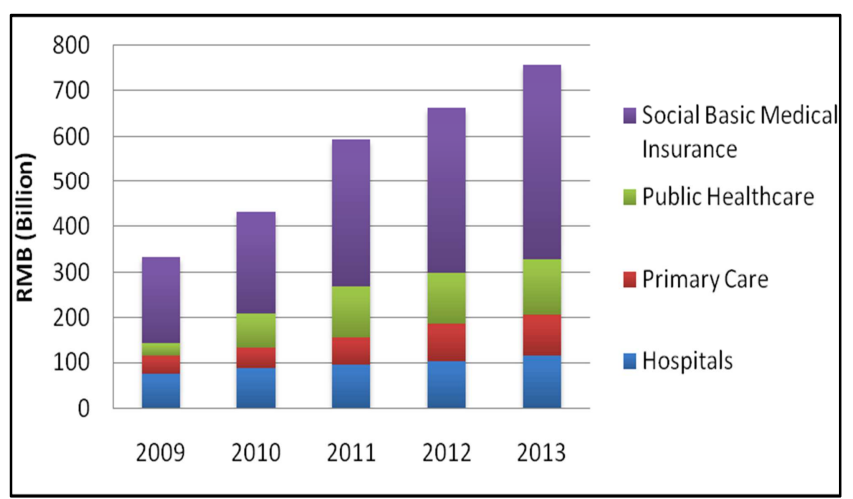

Figure 1. The flow of government expenditure on health.

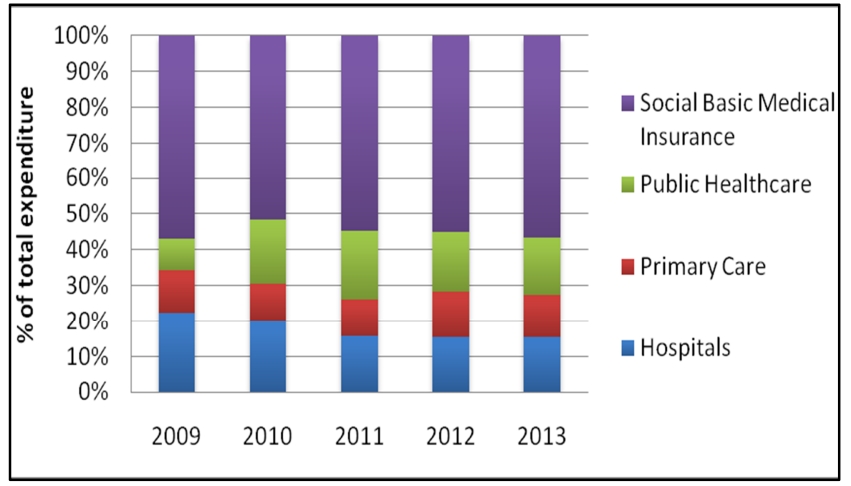

Figure 2. The proportion of the flow of government expenditure on health. 


\subsection{Table 1-5}

Table 1. The health care resource allocation during healthcare system reform from 2009 to 2013.

\begin{tabular}{|c|c|c|c|c|c|c|c|c|c|c|c|c|c|c|}
\hline \multirow{3}{*}{ Year } & \multicolumn{7}{|c|}{ Medical And Healthcare Professionals } & \multicolumn{7}{|c|}{ Healthcare-Associated Professionals } \\
\hline & \multirow[t]{2}{*}{$\begin{array}{l}\text { Total } \\
\text { workers } \\
\end{array}$} & \multicolumn{2}{|l|}{ Hospital } & \multicolumn{2}{|c|}{$\begin{array}{l}\text { Primary Care } \\
\text { Facilities }\end{array}$} & \multicolumn{2}{|c|}{$\begin{array}{l}\text { Public Health } \\
\text { Institutions }\end{array}$} & \multirow[t]{2}{*}{$\begin{array}{l}\text { Total } \\
\text { workers }\end{array}$} & \multicolumn{2}{|l|}{ Hospital } & \multicolumn{2}{|c|}{$\begin{array}{l}\text { Primary Care } \\
\text { Facilities }\end{array}$} & \multicolumn{2}{|c|}{$\begin{array}{l}\text { Public Health } \\
\text { Institutions }\end{array}$} \\
\hline & & Numbers & $\%$ & Numbers & $\%$ & Numbers & $\%$ & & Numbers & $\%$ & Numbers & $\%$ & Numbers & $\%$ \\
\hline 2009 & 778.1 & 395.8 & 50.9 & 315.2 & 40.5 & 60.1 & 8.6 & 553.5 & 320.0 & 57.8 & 183.3 & 33.1 & 46.6 & 8.4 \\
\hline 2010 & 820.8 & 422.7 & 51.5 & 328.2 & 40.0 & 62.5 & 8.5 & 587.6 & 343.8 & 58.5 & 191.4 & 32.6 & 48.7 & 8.3 \\
\hline 2011 & 861.6 & 452.7 & 52.5 & 337.5 & 39.2 & 64.1 & 8.3 & 620.3 & 370.6 & 59.7 & 196.3 & 31.6 & 49.8 & 8.0 \\
\hline 2012 & 911.9 & 493.7 & 54.1 & 343.7 & 37.7 & 67.0 & 8.2 & 667.9 & 405.8 & 60.8 & 205.2 & 30.7 & 53.2 & 8.0 \\
\hline 2013 & 979.0 & 537.1 & 54.9 & 351.4 & 35.9 & 82.6 & 8.4 & 721.1 & 442.5 & 61.4 & 213.8 & 29.6 & 60.9 & 8.4 \\
\hline
\end{tabular}

Data resources: the Statistical Bulletin of China's Health Development issued by National Health and Family Planning Commission every year during 2009-2013.Unit of numbers: 10,000.

Table 2. Contribution of China healthcare financial resources from 2009 to 2013.

\begin{tabular}{llllllll}
\hline \multirow{2}{*}{ Year } & \multicolumn{7}{c}{ Expenditures } \\
\cline { 2 - 8 } & Total & Government & \% & Social & \% & Out-Of-Pocket & \% \\
\hline 2009 & 1754.2 & 481.6 & 27.46 & 615.4 & 35.08 & 657.1 & 37.46 \\
2010 & 1998 & 573.2 & 28.69 & 719.7 & 36.02 & 705.1 & 35.29 \\
2011 & 2434.6 & 746.4 & 30.66 & 841.6 & 34.57 & 846.5 & 34.77 \\
2012 & 2811.9 & 843.2 & 29.99 & 1003.1 & 35.67 & 965.6 & 34.34 \\
2013 & 3166.9 & 954.6 & 30.14 & 1139.4 & 35.98 & 1072.9 & 33.88 \\
\hline
\end{tabular}

The data of government health expenditure were obtained from Annual National Public Fiscal Expenditure Data released by the Financial Ministry of the People's Republic of China from 2009 to 2013; Unit: Billion RMB ( $¥$ ).

Table 3. Components of China government health care expenditure from 2009 to 2013

\begin{tabular}{ccllllllll}
\hline Year & Government Health Care Expenditures & \multicolumn{2}{c}{ Hospitals } & \multicolumn{2}{c}{ Primary Care } & \multicolumn{2}{c}{ Public Healthcare } & \multicolumn{2}{c}{ Social Basic Medical Insurance } \\
\hline & RMB & RMB & \% & RMB & \% & RMB & \% & RMB & \% \\
\hline 2009 & 399.4 & 74.2 & 18.6 & 39.5 & 9.9 & 29.3 & 7.3 & 189.2 & 47.4 \\
2010 & 480.4 & 87.6 & 18.2 & 44.8 & 9.3 & 76.9 & 16.0 & 222.8 & 46.4 \\
2011 & 643.0 & 94.0 & 14.6 & 61.4 & 9.6 & 111.7 & 17.4 & 325.1 & 50.6 \\
2012 & 724.5 & 101.3 & 14.0 & 86.3 & 11.9 & 110.2 & 15.2 & 365.7 & 50.5 \\
2013 & 828.0 & 115.7 & 14.0 & 91.8 & 11.1 & 120.6 & 14.6 & 429.4 & 51.9 \\
\hline
\end{tabular}

Data sources: Annual National Public Fiscal Expenditure Data released by the Financial Ministry of the People's Republic of China from 2009 to 2013. \%, percentage of Government Health Care Expenditures; Unit: Unit: Billion RMB (Y)

Table 4. Healthcare service demands and utilization rate.

\begin{tabular}{ccccc}
\hline Year & $\begin{array}{c}\text { Annual Patient Visiting(Billion } \\
\text { Times) }\end{array}$ & $\begin{array}{c}\text { Annual Clinic Visiting Per } \\
\text { Person(Times) }\end{array}$ & $\begin{array}{c}\text { Annual Hospital Discharged(Million } \\
\text { person) }\end{array}$ & $\begin{array}{c}\text { Hospital Admission } \\
\text { Rates (\%) }\end{array}$ \\
\hline 2009 & 54.90 & 4.20 & 132.50 & 9.90 \\
2010 & 58.40 & 4.34 & 141.74 & 10.50 \\
2011 & 62.70 & 4.63 & 152.98 & 11.30 \\
2012 & 68.90 & 5.10 & 178.12 & 13.20 \\
2013 & 73.10 & 5.40 & 192.15 & 14.10 \\
\hline
\end{tabular}

Data sources: the Statistical Bulletin of China's Health Development" issued by National Health and Family Planning Commission every year during $2009-2013$.

Table 5. Contributions of healthcare expenditures.

\begin{tabular}{lllllllll}
\hline Year & $\begin{array}{l}\text { Total } \\
\text { Healthcare } \\
\text { Expenditures } \\
\text { (Trillion) }\end{array}$ & $\begin{array}{l}\text { Healthcare } \\
\text { Expenditures } \\
\text { In GDP (\%) }\end{array}$ & $\begin{array}{l}\text { Out-Of-Poc } \\
\text { ket Mone } \\
\text { (Billion) }\end{array}$ & $\begin{array}{l}\text { NCMS } \\
\text { (Billion) }\end{array}$ & $\begin{array}{l}\text { URBMI } \\
\text { (Billion) }\end{array}$ & $\begin{array}{l}\text { UEBMI } \\
\text { (Billion) }\end{array}$ & $\begin{array}{l}\text { Basic Medical } \\
\text { Insurance } \\
\text { (Billion) }\end{array}$ & $\begin{array}{l}\text { Percentage of out-of-pocket } \\
\text { health care expenditures per } \\
\text { capita in total health care } \\
\text { expenditures (\%) }\end{array}$ \\
\hline 2009 & 1.75 & 5.15 & 657.1 & 92.3 & --- & 263.0 & 355.3 & 64.91 \\
2010 & 1.99 & 4.98 & 705.1 & 118.8 & --- & 327.2 & 445.9 & 61.26 \\
2011 & 2.43 & 5.15 & 846.5 & 171.0 & 41.3 & 401.8 & 614.2 & 57.95 \\
2012 & 2.81 & 5.41 & 965.6 & 240.8 & 67.5 & 486.9 & 795.2 & 54.84 \\
2013 & 3.17 & 5.57 & 1072.9 & 290.9 & 97.1 & 583.0 & 971.0 & 52.49 \\
\hline
\end{tabular}

Data sources: China statistical yearbook in 2014. 


\section{Discussion}

In present retrospective study, we found that since China health care reform in 2009, the resources of health care, including human and financial resources, migrated towards disease "treatment" from disease "prevention". Along with extremely increased the healthcare expenditures, the public healthy was not improved as expected, and the resident out-of-pocket payment for healthcare was increased significantly, especially in rural population.

Healthcare resources migrated from "prevention" to "treatment"

From 2009 to 2013, the healthcare professionals had relocated to hospitals significantly for "treatment" disease from primary facilities. Professionals in public health institutions, increased slightly, but the primary care professionals, who served as "gatekeeper" for residents' healthy, declined progressively.

Moreover, the expenditures for healthcare mainly spent at hospital for disease "treatment". One of the potential reasons might relate to the strategies of China's healthcare reform. In the general plan of China's health care reform, the total of the five key reform tasks, four for "disease treatment" design, including: the establishment of universal coverage of basic medical insurance system, the establishment of national essential drug system, the reform of public hospitals, improve the basic medical and health service system. However, only one for the "disease prevention" of reform measures that promote basic public health services gradually equalization. [10] Obviously, the focus of China's health care reform is "disease treatment", belittled a very important job, and that is disease prevention. The chronic disease hazards were studied and predicted by LeiHaichao in early 1996. [11, 12] The "alarm" about Chinese prevalence rate of chronic diseases increasing rapidly has been mentioned as early as in 2003. [13] Chinese chronic disease prevalence increased by 5 percentage points from 2003 to 2008. [14] Previous studies suggested that to against rapid increase in the prevalence rate of chronic diseases, the elimination and/or control of the risk factors were the critical steps in chronic disease prevention and intervention, instead of the treatment. $[15,16]$ Another reason might be due to the reimburse policy of healthcare insurance in China. In tradition, "treatment" was paid more attention to "prevention". Therefore, most health insurance paid cost in-hospital patients only. Then there was a rapid increase in demand of in-hospital services (Table 4), which caused the overuse of medical services, and increased total health expenditure and medical costs obviously. Comparing the data between the Fourth and Fifth National Health Services Survey in 2008 and 2013 respectively, all clinic visiting increased from $62.4 \%$ in 2008 to $84.4 \%$ in 2013 . [14, 17]

Increased prevalence of chronic diseases

Lacking an effective primary care system, most hospitals were severely overwhelmed. This problem has been accelerated by reimbursement policy, aging and expansion of healthcare insurance coverage. In China, most patients sought treatment in the highest-level hospital (class III), because the other hospitals or facilities were thought to deliver poor healthcare, including, doctor's skill, facility equipment, medicine. Therefore, the government launched a new strategy to improve healthcare at "gatekeeper" by establish community healthcare center, and primary care facilities in rural area. Also, the government recently announced resident standard training program to link the class III hospitals with primary care facilities to improve the technics of general physicians. Another factor attracted patients to Class III hospitals is the essential drug list. In primary care facilities, prescription on the expensive drug was limited. Therefore, the adoption of standard treatment guideline, installment of performance-monitoring mechanism, and minimization of variations in doctors' skill will be the major direction for China healthcare reform. China should strengthen the primary health care personnel, it is particularly important.

In reality, although the primary prevention of the disease after treatment compared with the disease, we can save more lives, most of the resources of the health system is still mainly spent on the treatment of disease. [18] In many countries, although the residents have health insurance, but they still face the risk of catastrophic health expenditure. [19, 20] World experience and lessons show that healthy development objectives and strategies of selection improper and wrong the first choice, not only to the life and health system performance at the expense of health will also be misconfigured lot of resources and low efficiency costs. If the continuation of treatment based health care model, not an elixir can save the current resource misallocation and inefficient health care system. To address this problem, many countries in the health policy objectives and its implementation at the national level as well as ways to reform the health system direction, showing a new trend, stressing that "prevention first" and pay attention to the role of preventive health care, to promote clinical the integration of medicine and public health, the health of the overall concern of the priority allocation of resources on preventive health interventions with good cost-effectiveness, by primary health care providers rather than relying on top-level medical institutions, to change the health system lack of integration, lack of sustainability, inefficient, unfair and costly situation. [21]

As a developing country, China faces an aging population and high incidence of non-communicable diseases such as multiple challenges, the Chinese health care model from "treatment" to "prevention" should be taken as soon as possible. Experiences in many developed countries, such as Finland, Britain, Canada, France and Germany's proved that many interventions for chronic disease prevention measures recommended in " Frame Convention of Tobacco Control " and multiple drug therapy interventions used for cardiovascular disease of high risk population are very economic and effective. [22-24] Moreover, control effect often appears in much shorter time than expected. Some Chinese chronic disease intervention proved that chronic 
disease intervention is not only cost effective, but also has long term effects on health improvement. [25, 26] The experience from developed countries shows that by reducing or eliminating risk factors, the residents' health will be improved in China in a year or several years, rather than decades usually imagined by people. [27, 28] Many studies suggest that the challenge of chronic diseases such as diabetes rate continues to rise, and to strengthen the non-communicable disease risk factors than focus on disease treatment interventions more important. [15, 29]

Increased healthcare expenditures and resident financial burden

Based on the goal of healthcare reform, China has achieved near-universal health insurance coverage by end of 2011. [30] Surveillance data from 2009 to 2013 indicated that there had been a significant increase in the total healthcare expenditures. [31] Government share the most of expenditures increased about 2 fold, which might due to development of universal basic health insurance coverage by government. However, the out-of-pocket payment for healthcare remains a major expense for most of Chinese. Although the coverage of depth was increased by involvement of other social insurance, like NCMS, URBMI, UEBMI, the proportion of personal health cash disbursement to the sum of personal health cash disbursement and medical insurance expenditures remained high. Over $50 \%$ of all healthcare costs were paid as premiums or out-of-pocket payments. Furthermore, the expenses were varies depending where that person lives, and the type of insurance for people with URBMI or UEBMI, which were funded by the central government, local governments, and individual paid premiums. Therefore, the populations in rural area paid more than populations in urban area. The disparities in healthcare expenses might become smaller, along with the economic development in rural area.

Hints for future

Based on the above analysis and discussion, the following policies were recommended. Firstly, the health care mode transformation from "treatment" to "prevention" in the future should be chosen for the priority strategy in Chinese medical reform, rather than the reform in public hospitals of "disease treatment". It is impossible that this transformation depends on markets, which needs the government to actively take the main responsibility. At present, the more pressing tasks are: to increase the number of personnel system of disease prevention and control, to improve the quality of personnel engaged in disease prevention and control, to strengthen the work input for disease prevention and control, and to do a good job of prevention and control work for key epidemic, especially in the prevention and control for chronic disease. At the same time, to play their full role in prevention and health care by increasing the professional and technical personnel in health institutions at grassroots. Secondly, with the opportunity of promoting the rules of law, determine residents' health goals by legislation, integrate health into all policies and play the full role of all aspects of society to improve the health level of residents. Thirdly, China should focus on residents' health goals, integrating the government policy, resources and fund dispersed in all departments to pay attention to people's health, integrating clinical medicine with public health to allocate resources priority in interventions of preventive health with good cost effect.

\section{Conclusion}

Since the implementation of healthcare system reform, the China government has extremely increased investment in healthcare resources to achieve universal basic health insurance coverage. Therefore, utilization of healthcare serves had substantially increased. However, the increase was unbalanced between hospitals and primary care facilities, and between diseases "treatment" and "prevention", which increased the expenditures and the out-of-pocket payments, decreased the efficiency of service delivery. Given above analysis, the priority strategy for China healthcare system reform was to transform from diseases "treatment" to "prevention".

\section{Acknowledgements}

We thank support of these funds, include China Medical Board (CMB) (G09-986, G09-946), People's Republic of China Ministry of Science and support key projects (2008BAI65B19), People's Republic of China Ministry of Education, philosophy and social science key projects (08JZD0022), People's Republic of China Ministry of Education, Humanities and Social Science Planning Fund (08JA790099), China of Social Science Foundation (04 BJY 020).

\section{References}

[1] Chen Z. Launch of the health-care reform plan in China [J]. Lancet, 2009, 373:1322-4.

[2] Qide Han. China's health care development is still facing serious challenges [J]. Chinese Journal of Health Policy, 2010, 3(5): 41 .

[3] The Central People's Government of People's Republic of China. Chinese government's health care reform plan [OL]. http://www.gov.cn/test/2009-04/08/content_1280069.htm.

[4] Winnie Chi-Man Yip, William C Hsiao, Wen Chen, Shanlian $\mathrm{Hu}$, Jin Ma, Alan Maynard. Early appraisal of China's huge and complex health-care reforms [J]. Lancet, 2012, 379: 833-42.

[5] Hui Wu, Li Liu, Yang Wang, Fei Gao, Xue Zhao and Lie Wang. Factors associated with burnout among Chinese hospital doctors: a cross-sectional study [J]. BMC Public Health, 2013, 13: 786 .

[6] Gonghuan Yang, Lingzhi Kong, Wenhua Zhao, Xia Wan, Yi Zhai, Lincoln C Chen, Jeff rey P Koplan. Emergence of chronic non-communicable diseases in China [J]. Lancet, 2008, 372: $1697-1705$.

[7] Xuling, Menqun. The fifth Chinese national health services survey results of two -- health service need, demand and utilization [J]. Chinese Journal of Health Informatics and Management, 2014, 11(3): 193-194. 
[8] Ministry of Finance of the people's Republic of China.China's public expenditure statement in 2013 [OL]. http://yss.mof.gov.cn/2013qgczjs/201407/t20140711 1111874 .html.

[9] China Insurance Regulatory Commission. China insurance statistics report in 2013 [OL]. http://www.circ.gov.cn/web/site0/tab5257/info3901864.htm.

[10] National Health and Family Planning Commission of the People's Republic of China. China's health care reform the recent focus on the implementation of the program (2009-2011) [OL].http://www.nhfpc.gov.cn/tigs/s9660/200904/4f690ccd55 c348ddabd3a3e6ad4d79f7.shtml.

[11] Lei hai-chao, Liuxing-zhu, Bian Ying. Study on prediction of costs of chronic diseases treatment in China [J]. Chinese Health Economics, 1996, 10: 18-19.

[12] Lei hai-chao, Liuxing-zhu, BianYing, etc. Study on morbidity of chronic diseases in the future trend in China [J]. Chinese Health Economics, 1996, 10: 7-9.

[13] Republic of China Ministry of Center for Health Statistics and Information. An Analysis Report of National Health Services Survey in China, 2003. [M]. Peking Union Medical College press, 2004, 1.

[14] Republic of China Ministry of Center for Health Statistics and Information. An Analysis Report of National Health Services Survey in China, 2008 [M]. Peking Union Medical College press, 2009, 12.

[15] Gonghuan Yang, Yu Wang, Yixin Zeng, et al. Rapid health transition in China, 1990-2010: fi ndings from the Global Burden of Disease Study 2010 [J]. Lancet, 2013, 381: 19872015.

[16] Meng Q, Xu L, Zhang Y et al. Trends in access to health services and financial protection in China between 2003 and 2011: a cross-sectional study [J]. Lancet, 2012, 379: 805-14.

[17] National Health and Family Planning Commission of the people's Republic of China. China Health and Family Planning Statistics Yearbook 2015 [M]. Peking Union Medical College press, 2015, 10 .

[18] Woolf S H. The need for perspective in evidence-based medicine [J]. JAMA, 1999. 282: 2358-2365.

[19] Christine Goeppel, Patricia Frenz, Peter Tinnemann, et al. Universal health coverage for elderly people with non-communicable diseases in low-income and middle-income countries: a cross-sectional analysis. Lancet, 2014,384, S6.
[20] Qun Meng, Ling Xu, Yaoguang Zhang, et al. Trends in access to health services and financial protection in. Lancet, 2012,379: 805-14.

[21] REN Ran. The New Direction for Health \& Health Reform Internationally: Enhancing the Role of Prevention Care [J]. Medicine \& Philosophy (Humanistic \& Social Medicine Edition), 2010, 31(4): 5-8.

[22] Asaria P, Chisholm D, Mathers C, et al. Chronic disease prevention: Health effects and financial costs of strategies to reduce salt intake and control tobacco use [J]. Lancet, 2007, 370 (9604): 2044-2053.

[23] Lim, SS. Gaziano TA, Gakidou E, etal. Prevention of cardiovascular disease in highrisk individuals in low-income and middle-income countries: Health effects and costs [J]. Lancet, 2007, 370(9604): 2054-2062.

[24] Jamison, DT, Breman JG, Measham AR, et al. Disease control priorities in developing countries [M]. New York: Oxford University Press, 2006.

[25] Wu X. G, Gu D F, Wu Y. F, et al. An evaluation on effectiveness of worksite based intervention for cardiovascular disease during 1974-1998 in Capital Iron and Steel Company of Beijing [J]. Journal of China Preventive edicine, 2003, 37 (2): 93-97.

[26] Li G, Zhang P, Wang J, et al. The long-term effect of lifestyle interventions to prevent diabetes in the China Da Qing Diabetes Prevention Study: A 20-year follow-up study [J]. Lancet, 2008, 371(9626): 1783-1789.

[27] Puska, P. 2002. Successful prevention of NCDs: 25 year experience with North Karelia Project in Finland [J]. Public Health Medicine, 202, 4(1): 5-7.

[28] Patricio V. Marquez P. Lead Health Specialist, et al. 2005. Dying too young. Addressing premature mortality and ill health due to non-communicable diseases and injuries in the Russian Federation [M]. Washington, DC: The World Bank, 2005.

[29] Juliana C N Chan, Yuying Zhang, Guang Ning. Diabetes in China: a societal solution for a personal challenge. Lancet Diabetes Endocrinol 2014, 2: 969-79.

[30] National Bureau of Statistics of the People's Republic of China. China Statistical Year book 2012 [M]. China Statistics Press, 2012, 9 .

[31] National Bureau of Statistics of the People's Republic of China. China Statistical Year book 2015 [M]. China Statistics Press, 2015, 10. 